\title{
História da Psicologia, por quê?
}

\author{
History of Psychology, why?
}

Historia de la psicología, ¿por qué?

\author{
Ana Maria Del Grossi Ferreira Mota* \\ Universidade Católica Dom Bosco - UCDB, Campo Grande, Mato Grosso do Sul, \\ Brasil
}

\author{
Bianca dos Santos Cara** \\ Universidade Católica Dom Bosco - UCDB, Campo Grande, Mato Grosso do Sul, \\ Brasil
}

\section{Rodrigo Lopes Miranda***}

Universidade Católica Dom Bosco - UCDB, Campo Grande, Mato Grosso do Sul, Brasil

\begin{abstract}
RESUMO
Recorrentemente, o psicólogo-historiador se vê diante da questão, endereçada por seus pares ou alunos: por que estudar História da Psicologia? Tal questão é tão recorrente que livros-texto de História da Psicologia reservam um espaço para apresentar respostas, justificativas, a tal provocação. Diante disso, este artigo endereça uma resposta a tal questão, a partir da hipótese de que a História da Psicologia é uma ferramenta para compreensão de rupturas e permanências de fenômenos históricos vinculados aos campos Psi e, esta compreensão, nos auxilia em uma visão mais crítica do presente. Para atingir tal objetivo, são apresentados dois exemplos de questões históricas, mais ainda contemporâneas, na Psicologia brasileira: (a) a definição de campos de atuação e técnicas de atuação do psicólogo e (b) discursos e práticas normatizantes com pessoas homossexuais. Assim, a partir de tais exemplos que nos permitem ver a história na Psicologia e, também, a Psicologia na história, conclui-se que a História da Psicologia pode, sim, contribuir com uma análise mais crítica do momento presente. Para tanto, faz-se necessário a pesquisa em História da Psicologia e o ensino de sua história, para uma formação crítica do psicólogo brasileiro.
\end{abstract}

Palavras-chave: História da Psicologia, História Social da Psicologia, Ensino de História da Psicologia.

\footnotetext{
ABSTRACT

Frequently, the psychologist-historian of Psychology finds himself faced with the question, addressed by his peers or students: why should we study the History of Psychology? Textbooks on the History of Psychology reserve some sections to present such justifications to their readers, indeed. Therefore, we aim to give an answer to that question, based on the hypothesis that the
} 
History of Psychology is a tool for understanding ruptures and permanencies of Psychological phenomena in the history, and this understanding helps us to build up a more critical view of the present. In order to achieve that goal, two examples of historical issues in Brazilian Psychology - that are still contemporary - are presented: (a) the definition of fields of application and their techniques, and (b) normative discourses and practices with homosexual people. Thus, from such examples that allow us to see history in Psychology and also Psychology in history, we conclude that the History of Psychology would contribute for a more critical analysis of the present. Therefore, it is necessary to research in History of Psychology and to teach its history, for a critical formation of the Brazilian psychologist.

Keywords: History of Psychology, Social History of Psychology, Teaching of History of Psychology.

\begin{abstract}
RESUMEN
Frecuentemente, el psicólogo-historiador se ve ante la cuestión, direccionada por sus pares o alumnos: ¿por qué estudiar Historia de la Psicología? Tal cuestión es tan recurrente que libros didácticos de Historia de la Psicología reservan un espacio para presentar respuestas, justificaciones, a tal provocación. Por lo tanto, este artículo brinda una respuesta a tal cuestión, a partir de la hipótesis de que la Historia de la Psicología constituye una herramienta para la comprensión de rupturas y permanencias de fenómenos históricos vinculados a los saberes Psi y que esta comprensión nos auxilia en una visión más crítica del presente. Para alcanzar tal objetivo, se presentan dos ejemplos de cuestiones históricas, más aún contemporáneas, en la Psicología brasileña: (a) la definición de campos de actuación y técnicas de actuación del psicólogo y (b) discursos y prácticas de normativización con personas homosexuales. Así, a partir de tales ejemplos que nos permiten ver la historia en la Psicología y, también, la Psicología en la historia, se concluye que la Historia de la Psicología sí puede contribuir a un análisis más crítico del momento presente. Para ello, se hace necesaria la investigación en Historia de la Psicología y la enseñanza de su historia, para una formación crítica del psicólogo brasileño.
\end{abstract}

Palabras claves: Historia de la Psicología, Historia Social de la Psicología, Enseñanza de la Historia de la Psicología.

O título deste trabalho se remete a um texto de Max Wertheimer, traduzido para o português-brasileiro, em 1998, quando da publicação da obra Historiografia da Psicologia Moderna (Brožek \& Massimi, 1998), cujo conteúdo elenca diversas razões pelas quais deveríamos estudar História da Psicologia. Este tipo de argumento tem sido recorrente em livros-texto de História da Psicologia, já que ele nos auxilia a compreender um conjunto de razões pelas quais tal conteúdo deveria ser estudado (e.g., Goodwin, 2012; Pickren \& Rutherford, 2010; Schultz \& Schultz, 2015). Neste cenário, de maneira geral, parece-nos que dois argumentos se destacam. Por um lado, na formação, em Psicologia, deveríamos aprender a história dos objetos de estudo, dos métodos e das técnicas psicológicas como forma de compreender como tais elementos compõem o presente. Isso tenderia à direção de produzir uma formação, potencialmente 
mais crítica, dos futuros psicólogos, já que, ao longo do tempo, eles perceberiam a maneira como os variados modelos de Psicologia se produziram. Por outro, só seria possível alimentar tal ensino se pudéssemos fomentar o campo da pesquisa em História da Psicologia. Assim, deveríamos pesquisar as formas pelas quais a Psicologia se constituiu como um campo do saber e uma profissão, ao longo do tempo, dialogando com diferentes condições intelectuais, econômicas, sociais e outras. Ou seja, os argumentos operam a partir da importância de ensinarmos o passado da Psicologia (sua história) para uma formação crítica do psicólogo, o que só seria possível pela pesquisa historiográfica da Psicologia (a História da Psicologia).

Esta formação crítica dos psicólogos e a contribuição que a História da Psicologia pode fornecer tem sido alvo de debates contemporâneos (Barnes \& Greer, 2014; Fierro, 2016; Vaugh-Blount, Rutherford, Baker, \& Johnson, 2009). No Brasil, o debate pode ser visto em, pelo menos, dois cenários. No primeiro, que aborda as Diretrizes Curriculares Nacionais, lê-se, em seu Art. 5o, que o ensino de fundamentos epistemológicos e históricos é necessário para uma formação crítica, em Psicologia (Ministério da Educação e Cultura [MEC], 2011). Assim, do ponto de vista da formação, observamos, claramente, a crença na importância do ensino da História da Psicologia. No segundo, campo da pesquisa e da organização científica, tivemos a criação de Grupos de Trabalho na Associação Nacional de Pesquisa e Pós-Graduação em Psicologia (ANPEPP); a criação da Sociedade Brasileira de História da Psicologia (SBHP); a editoração de periódicos específicos, entre outros. Todavia, apesar deste cenário, é recorrente que o psicólogo-historiador ouça: "Por que temos de estudar História da Psicologia?" Este, por sua vez, precisará se esmerar em justificativas, a fim de clarificar tal questão. Ou seja, parece que mesmo com um cenário promissor para o ensino e a pesquisa em História da Psicologia, no país, há demandas contemporâneas que, correntemente, colocam o psicólogo-historiador diante da pergunta: "História da Psicologia, por quê?".

Este texto procura responder à tal pergunta, a partir da perspectivade de que estudar a história, nos ajuda a compreender como algumas escolhas feitas, no passado, impactam na contemporaneidade $e$, inclusive, atualizam-se no presente, fornecendo condições para que se possa contribuir com debates atuais, no campo da Psicologia (cf. Jansz \& van Drunen, 2004; Portugal, Facchinetti, \& Castro, 2018). Espera-se, entretanto, fugir do perigo do presentismo, i.e., atribuir uma linearidade causal entre o passado e o presente, interpretando os eventos passados a partir de valores e ideias contemporâneas. Para tanto, elencamos dois estudos historiográficos que se relacionam a debates contemporâneos, na Psicologia, cuja história pode nos ajudar em uma melhor compreensão da atualidade. Os dois são estudos em História Crítica 
da Psicologia (Danziger, 1985) e se inserem na possibilidade de historicizarmos os objetos científicos, i.e., como ocorre, ao longo do tempo, a articulação entre objetos, teorias e práticas científicoprofissionais na conformação de problemáticas da ciência (cf. Danziger, 1993, 2003; Daston, 2000). A documentação primária de ambos foi textual, acarretando na necessidade do uso de Análise Documental (Luchese, 2014) como estratégia de interpretação dos sentidos de tais documentos. O primeiro estudo se refere ao debate sobre a prática profissional do psicólogo, no campo da saúde mental, sobretudo no que diz respeito ao uso de métodos e técnicas diagnósticas, especialmente a partir daquela que ficou conhecida como a Lei do Ato Médico-Lei no 12.842 (2013). O segundo trata sobre as discussões atuais, promovidas pelo Projeto de Decreto Legislativo $\mathrm{n}$ - 234 (2011), em torno da prática profissional do psicólogo em relação à questão da orientação sexual, no caso a homossexualidade. Estima-se, ao final, mostrar que estudar a História da Psicologia nos habilita a compreender certas escolhas do passado e, também, propicia a que vejamos rupturas e permanências, na história, contribuindo com reflexões sobre questões contemporâneas. Inclusive, nos ajudando a ver como tais questões conformam a produção de conhecimentos e práticas psicológicas, ao longo da história da Psicologia, no país.

\section{Conformando práticas profissionais e objetos de trabalho}

Em 2002, o Projeto de Lei no 268 ficou conhecido como "Lei do Ato Médico". Durante os trâmites legais desta legislação, mais tarde, em 2006, ele foi reapresentado como o Projeto de Lei no 7703 e, em 2013, foi sancionado como Lei $\mathrm{n}$ - 12.842 . No Projeto de Lei $\mathrm{n}$ o 7703 , o seu artigo 40 definia quais seriam as atividades privativas do médico e, entre elas, estaria a "formulação de diagnóstico nosológico e a respectiva prescrição terapêutica." Isso implicaria que o diagnóstico nosológico, referente ao diagnóstico de patologias, configuraria em uma obrigação, exclusivamente, de médicos. Tal fato se deveria, além de outros, ao currículo de formação médica, no que tange ao diagnóstico semiológico ampliado. A definição, em tese, não implicaria em diagnósticos funcionais ou de sofrimento mental. Todavia, no campo prático, poderia haver uma área cinzenta em que um paciente, interessado em psicoterapia, procurasse um médico, primeiramente, antes de seu encaminhamento a um psicoterapeuta. Após alguns embates entre comunidades de médicos, psicólogos, assistentes sociais e outros, o artigo foi vetado, uma vez que a prescrição de tratamento se tornaria prerrogativa do médico. No entanto, condições como essa ainda parecem contemporâneas, i.e., debates 
sobre a prática profissional do psicólogo, no campo da saúde mental, bem como os embates com outras comunidades, sobre o uso de métodos e técnicas diagnósticas, voltam a ser discussões no campo da saúde.

Embates como esses parecem recorrentes na história da Psicologia brasileira, embora eles não estejam editados nos mesmos moldes ou no que se refere aos mesmos objetos. Em 27 de agosto de 1962, foi aprovada a Lei $\mathrm{n}$ o 4.119 que, até os dias atuais, regulamenta a formação e o exercício profissional do psicólogo. A efetiva aprovação desta lei se deu após cerca de dez anos de trâmite no congresso, em decorrência de debates sobre campos de atuação, teóricas e objetos de trabalho (Baptista, 2009, 2010; Mota \& Miranda, 2017). Um campo de tensões ocorreu, especificamente, com a Medicina, em decorrência de embates em torno da responsabilidade sobre a Psicologia Clínica, i.e., a matéria seria campo de atuação médica ou psicológica? Este tipo de debate, inclusive, não esteve presente apenas no contexto brasileiro. Estudos contemporâneos sinalizam que entre as décadas de 1950 e 1980, nos Estados Unidos da América (EUA) e na Argentina, houve controvérsias entre a Psicologia, a Psiquiatria e a Psicanálise (Buchanan, 2003; Klappenbach, 2000a, $2000 \mathrm{~b})$. Tais controvérsias envolviam o estabelecimento de limites legais e científico-profissionais entre tais campos, com foco específico na Psicologia Clínica e, particularmente, no monopólio da psicoterapia como campo de atuação profissional. No contexto brasileiro, este debate envolveu diferentes aspectos, tais como diagnósticos, terapêuticas e a definição do objeto da prática do profissional psicólogo. Um dos impactos de tais embates está na Lei no 4.119 (1962), em que ficou estabelecido como função privativa do psicólogo o uso de métodos e técnicas psicológicas para, entre outros, realizar - "diagnóstico psicológico" e a "solução de problemas de ajustamento." Entretanto, ao buscar, na referida lei, o que seriam os "problemas de ajustamento" a serem solucionados e quais seriam os "métodos e técnicas psicológicas" hábeis para tal solução, inexistem tais respostas.

Pela Lei no 4.119 (1962), consideram-se os "problemas de ajustamento" um objeto para atuação do profissional de Psicologia. Decorre, daí, que o conceito de ajustamento se torna relevante no contexto da regulamentação da prática do psicólogo, no Brasil. No entanto, a proposta de investigar tal conceito se torna um tanto complexa, uma vez que, parece que o conceito de ajustamento se origina de uma construção de conceitos que procederam da Biologia e da Etologia. Em nível estritamente biológico, "ajustamento" revela-se pela sobrevivência, sendo possível elencar sete critérios e uma avaliação do grau - ou nível de ajustamento - alcançado pelo indivíduo (Penna, n.d., p. 78). Ainda nas palavras deste autor: 
o self-insight, isto é, o autoconhecimento, a autoestima, o sentimento de segurança, a capacidade de dar e receber afeto, a satisfação de necessidades físicas, a capacidade de produção ou de trabalho e a ausência de tensões excessivas e de hipersensibilidade. Distorções envolvendo esses aspectos do comportamento conduzem-nos a conceituação de neurose e, consequentemente, a constatação de desajustamento.

Ao considerar o contexto biológico, os conceitos de "ajustamento" se equivalem ao de "adaptação". No entanto, quando o enfoque é psicológico, "ajustamento" se refere às exigências psicossociais, nas quais o self se constitui. Na década de 1980, Dorin (1980), apresentou a seguinte definição: "ajustamento - operação de relacionamento do indivíduo com o ambiente. Relações entre o indivíduo e o meio social durante as atividades que visam a satisfação dos seus motivos" (p. 12). Parece que, nos anos em torno da regulamentação da profissão do psicólogo, "problemas de ajustamento" relacionava-se às motivações biológicas e às relações sociais estabelecidas.

Ainda na busca de definições para tais "problemas", deparamo-nos com alguns aspectos marcantes, ainda tendo como referência documentos legais, como o uso de métodos e técnicas psicológicas, as quais configurariam função privativa do profissional psicólogo, desde a regulamentação da profissão. No entanto, até o ano 2000, do ponto de vista legal, não parece haver clareza sobre o uso de métodos e técnicas psicológicas. Naquele ano, por meio da Resolução no 018 (2000), o Conselho Federal de Psicologia (CFP) esclareceu distinções entre o que são métodos, técnicas e, particularmente, métodos psicológicos. O primeiro compreende um conjunto sistemático de procedimentos para produção ou aplicação de conhecimentos enquanto as técnicas são atividades específicas orientadas por aqueles métodos. Por fim, os métodos psicológicos seriam "[um] conjunto sistemático de procedimentos aplicados à compreensão e intervenção em fenômenos psíquicos nas suas interfaces com os processos biológicos e socioculturais" (p.3), ou seja, parece que, apenas a partir de 2000, o CFP passou a estabelecer, por meio de Resoluções, parâmetros técnicos e metodológicos para o exercício das funções do psicólogo, mas ainda não ficam claros quais são os "problemas de ajustamento" que seriam objeto das "soluções" produzidas pelos psicólogos. Dessa forma, as fontes legais nos sugerem pouca clareza sobre quais seriam os objetos de trabalho do fazer psicológico, o que, por sua vez, poderia abrir espaço para a ressurgência de embates com a classe médica, como, por exemplo, a já citada Lei do Ato Médico.

Ainda nesta seara, Castro e Alcântara (2011) afirmam que a Lei no 4.119 “... suprimiu o termo psicoterapia, concedendo ao psicólogo o 
direito de atuar na clínica dentro do que se convencionou chamar de solução de problemas de ajustamento" ( $p$. 46). Isto é, além da compreensão dos "problemas de ajustamento", seria necessário compreender "os métodos e técnicas" para sua "solução". Aqui residia, então, uma preocupação com a psicoterapia, que consiste em outro aspecto em discussão no ano de 2000, quando a Resolução CFP no 010 (2000) a estabeleceu como prática do psicólogo. A Resolução (2000, p.2) define psicoterapia:

A Psicoterapia é prática do psicólogo por se constituir, técnica e conceitualmente, um processo científico de compreensão, análise e intervenção que se realiza através da aplicação sistematizada e controlada de métodos e técnicas psicológicas reconhecidos pela ciência, pela prática e pela ética profissional, promovendo a saúde mental e propiciando condições para o enfrentamento de conflitos e/ou transtornos psíquicos de indivíduos ou grupos.

As terapêuticas eram um dos pontos de confronto entre as comunidades de médicos e psicólogos, ainda nas décadas de 1950 e 1960 (Castro \& Alcântara, 2011; Jacó-Vilela, 1999; Mota \& Miranda, 2017). O conflito se estabeleceu, especificamente, no período em torno dos primeiros projetos de lei referentes à regulamentação da profissão do psicólogo e eram marcados por disputas de campo de atuação referentes à psicoterapia como terapêutica de tratamentos em saúde mental. Nos dias atuais, a Resolução CFP no 013 (2007) institui o direito de especialidade clínica ao psicólogo, ao qual cabe a "solução de problemas de ajustamentos." Nesse documento, lemos que "solução de problemas de ajustamento - é o processo que propicia condições de auto realização, de convivência e de desempenho para o indivíduo, o grupo, a instituição e a comunidade, mediante métodos psicológicos preventivos, psicoterápicos e de reabilitação" (p. 2-3). Esta proposta perpetua a carência de termos que definam "problemas de ajustamento." No entanto, fornece apontamentos de como solucionar tais problemas. Assim, em 2017, o Projeto de Lei No. 7726 colocou em discussão o uso privativo do termo "psicoterapia" para Psicólogos e Psiquiatras. Ainda assim, a Resolução do CFP e o Projeto de Lei não garantem exclusividade, ao psicólogo, para o uso de psicoterapia e de outras técnicas, na solução de problemas de ajustamento, além de não definir o que seriam os "problemas de ajustamento".

Dessa forma, a literatura nos mostra que, quando nos deparamos, na Lei n. 4.119 (1962), com a expressão "solução de problemas de ajustamento" como campo de atuação do psicólogo, a ideia daquilo que poderia ser "ajustado" e de como "solucionar o que estaria desajustado" parece não estar suficientemente clara. Ainda hoje, o 
reflexo de tais confrontos continua a ressoar, na profissão do psicólogo, quando observados os problemas sobre a definição, tanto do que são os métodos e as técnicas psicológicas quanto do seu objeto, enquanto determinada como função do psicólogo aquela de "solucionar problemas de ajustamento." Um dos "problemas de ajustamento" que ressoa, até a atualidade, refere-se à relação entre psicoterapia e homossexualidade.

\section{A terapêutica da homossexualidade como rastros de um passado}

No ano de 2011, o Projeto do Decreto Legislativo No. 234 alegou que o CFP, por meio da Resolução no 001 (1999), estaria impedindo, ou restringindo, o atendimento psicológico a pessoas homossexuais. Tal projeto acabou sustando os efeitos de dois dispositivos da referida Resolução que normatizavam e orientavam a prática dos psicólogos nas questões relativas à orientação sexual. O CFP se posicionou, à época, alegando não contestar o sofrimento a que as pessoas homossexuais são acometidas, mas o atribuindo às condições sociais que conferem sentido pejorativo às expressões e vivências das diversas orientações sexuais, e.g., homossexualidade, bissexualidade, heterossexualidade, entre outros (CFP, 2017). Tal cenário de controvérsias a respeito da homossexualidade, no campo da saúde mental, não parece ser apenas contemporâneo. Durante os anos de processo legal, na década de 1950, até a regulamentação da profissão do psicólogo, pela Lei n. 4.119 (1962), a expressão "solução de problemas de ajustamento" foi usada para substituir palavras como "psicoterapia" e "tratamento de problemas emocionais", o que viabilizou a prática do psicólogo para tais funções, no país. Neste mesmo recorte temporal, o Manual Diagnóstico e Estatístico de Transtornos Mentais (DSM-I) incluía a homossexualidade no diagnóstico de "desvio sexual". Esse cenário sinalizava que a homossexualidade parecia ser uma categoria dentre os "problemas de ajustamento", cuja solução caberia aos psicólogos. A historiografia das Ciências e mais particularmente a História dos campos Psi - Psicologia, Psiquiatria e Psicanálise - tem discutido aspectos socioculturais envolvidos com tal clínica da homossexualidade (Dickinson, 2015; Erzen, 2006; Mariano, 2016). Estas pesquisas têm nos mostrado elementos socioculturais que conformaram a relação entre Psicologia Clínica e a homossexualidade como diretrizes diagnóstica. Em tais trabalhos, vemos desde debates sobre diferentes versões do DSM e a patologização de comportamentos homoafetivos até a relação entre discursos e práticas religiosas em um "...esforço de mudar e converter homens gays e lésbicas em cristãos não-homossexuais" (Erzen, 2006, p.3). 
Para a presente reflexão, referindo-se ao Brasil, tomaremos como fontes primárias artigos publicados nos dois primeiros periódicos brasileiros especificamente direcionados à Psicologia: os Arquivos Brasileiros de Psicotécnica e o Boletim de Psicologia. Essas fontes poderiam nos aproximar, por meio das formas de compreensão da "homossexualidade" e das formas de "solucioná-la", de um grupo de pessoas que estiveram próximas do debate da Lei n. 4.119 (Baptista, 2009, 2010).

O recorte temporal encontra-se entre as décadas de 1960 e 1970, período em que assistimos à eclosão de diferentes movimentos de direitos civis e contraculturais, tais como a segunda onda feminista, o movimento hippie, o fortalecimento do movimento negro e o debate sobre direitos civis homossexuais. Particularmente no Brasil, aspectos daquele cenário geral também se faziam presentes, como, por exemplo, com a organização e publicação de jornais específicos para aqueles grupos marginalizados (cf. Lampião de Esquina, 1978-1981). Além disso, vemos a ditadura civil-militar, marcada, dentre outros, por um processo de industrialização, influenciado por mudanças político-econômicas de base liberal, que provocaram certo crescimento urbano (Fausto, 2002). Tais mudanças propiciaram o desenvolvimento da Psicologia, especialmente de forma a acompanhar as demandas de uma sociedade moderna, i.e., esta ciência poderia contribuir para o desenvolvimento industrial, para pensar condições para a higiene mental, bem como para atuar na educação (Massimi, 2010; Russo, 2010). Nesse ínterim, parece que a preocupação com questões relacionadas à saúde mental da população era relevante, uma vez que refletia no desenvolvimento econômico e na ordem social.

Nessa direção, a literatura nos mostra que a compreensão de saúde e doença mental, à época, relacionava-se ao resultado do equilíbrio/desequilíbrio da pessoa e ao meio no qual estava inserida, em que o coletivo apresentaria padrões a serem seguidos (e.g., Mota, Castro Neto \& Miranda, 2016). Nas fontes primárias, vemos que a pessoa considerada saudável teria a capacidade de estabelecer relações harmoniosas com outras pessoas, de forma que satisfizesse, equilibradamente, seus impulsos e, assim, contribuísse com as modificações do ambiente (Escardó \& Giberti, 1961). Por sua vez, a pessoa não saudável teria comportamentos que não eram culturalmente esperados, o que gerava sofrimento psicológico, pois causava uma desintegração "bio-psico-anímico-existencial da personalidade" (Arruda, 1968). Aqui, caberia o ajustamento, i.e., a adaptação às demandas sociais, como forma de minimizar o sofrimento psíquico associado ao desequilíbrio na relação sujeito e ambiente social. Um exemplo desse desequilíbrio foi a homossexualidade (Adrados, 1964; Baez-Sampaio, 1962; Silva, 1967). Franco Filho (1972), por exemplo, nos diz: 
fala-se muito frequentemente que a homossexualidade não deveria ser encarada como problema de vez que, ela expressaria simplesmente a existência de uma opção diferente no campo sexual, a ter seu lugar ao sol, em condições de igualdade com as opções heterossexuais. Isso se deveria ao fato de haver ao lado do masculino e do feminino, um "terceiro sexo" que se caracterizaria pela eleição homossexual do objeto (p.3-4).

Apesar de diferentes palavras que contemporaneamente entrariam em debate -e.g., "opção" -, as fontes nos sugerem que havia controvérsias em torno de tal concepção, i.e., aproximações e tensionamentos em perspectivas diferentes sobre 0 que seria homossexualidade e em como aborda-la clinicamente. Inclusive, se tal abordagem clínica deveria compreendê-la como "doença" (Simon, 1972) e, portanto, homossexualismo, ou como "opção" e, assim, homossexualidade.

A descrição clínica geral, em parte das fontes analisadas, consistia em prevalência do sexo masculino, entre treze e vinte anos (Adrados, 1964; Baez-Sampaio, 1962; Silva, 1967). Os critérios diagnósticos variaram entre explicações baseadas em: a) expectativas de gênero, b) aspectos biológicos e c) Psicanálise. Quanto às expectativas de gênero, as explicações para as "tendências homossexuais" se davam mediante a incoerência do comportamento do sujeito ao considerar os estereótipos, e.g., "Tem queda para desenho. Sente vergonha de andar malvestido. Gosta de luxo e conforto. Gosta de usar perfumes" (Baez-Sampaio, 1962, p.5), ou, ainda, "seu gosto por bailes e dança; natação é o único esporte que pratica; assiste a futebol de vez em quando. Gosta muito de cinema e teatro" (Silva, 1967, p.91). Assim, nos parece que o "diagnóstico" da homossexualidade se daria pela adequação - ou não - dos comportamentos publicamente observáveis e interesses do sujeito ao que era socialmente esperado. Inclusive, com uma compreensão de "o sexo do indivíduo é o conjunto de suas características genéticas, gonadais, hormonais, anatômicas e psicológicas, incluindo estas últimas as atitudes da pessoa frente à sociedade - 'gender role' - e a maneira pela qual a sociedade rotula o indivíduo" (Epps, 1972, p.11). Entretanto, havia aqueles que consideravam a homossexualidade um quadro psicopatológico, conforme descritos no DSM e, para tais autores, deveria haver o debate e a promoção de práticas "da prevenção da homossexualidade masculina" (Simon, 1972, p.19; ver Figura 1). 
Figura 1. Proposta de compreensão da homossexualidade e aspectos da prevenção.

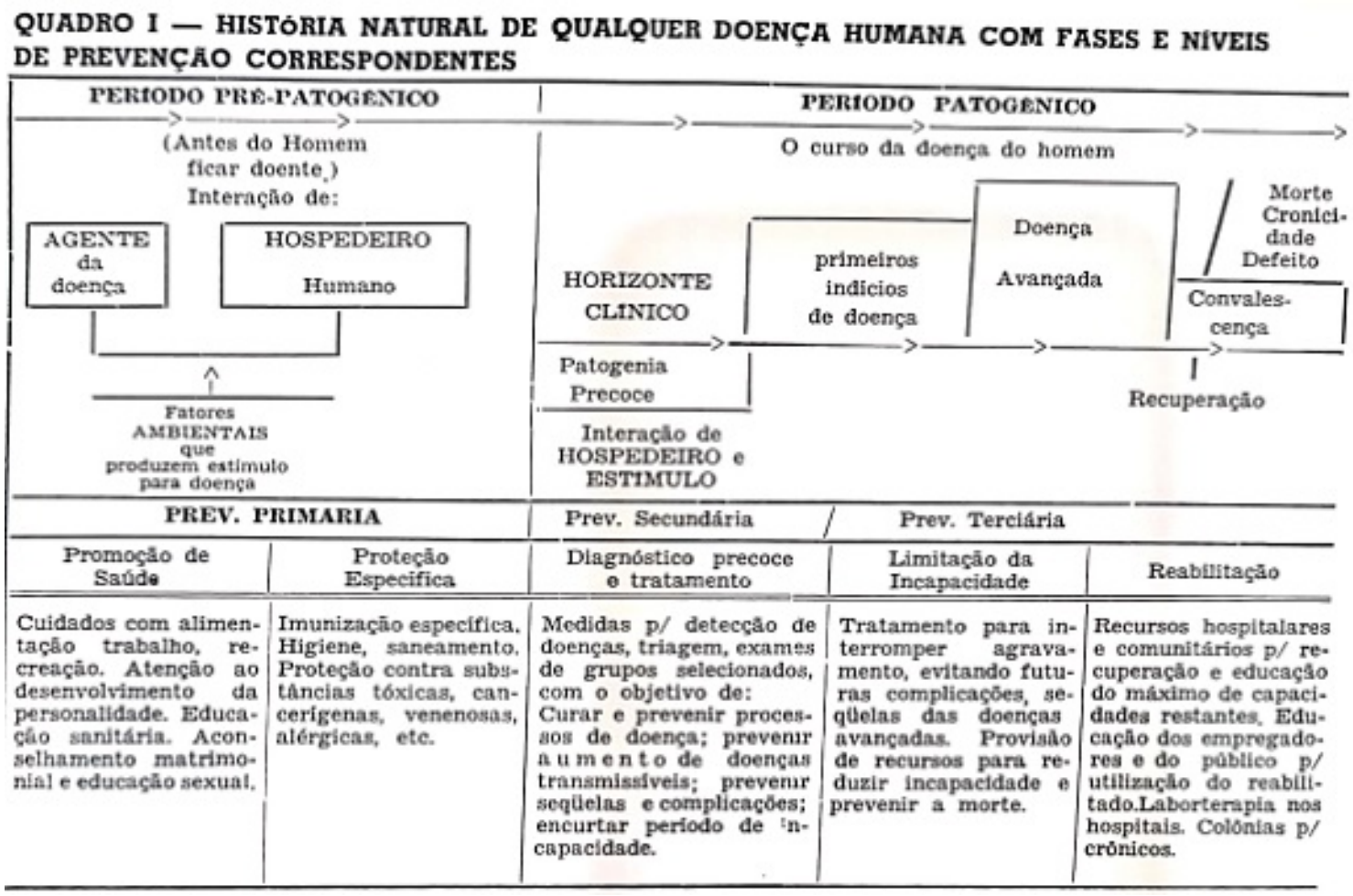

Fonte: Simon, 1972, p.21.

Houve aspectos biológicos relacionados ao diagnóstico de homossexualidade, como "comportamentos homossexuais decorrentes de alterações glandulares" (Adrados, 1964, p.68)e o "aperfeiçoamento das técnicas de dosagens hormonais [que proporcionaria] novas perspectivas no estudo da etiopateogenia da homossexualidade" (Epps, 1972, p.14). Entretanto, a maioria das descrições e explicações, nos textos analisados, apontaram aspectos nosológicos psicanalíticos, como, por exemplo, "homossexualidade secundária", "verdadeira homossexualidade" e "casos de homossexualidade, um deles portador de homossexualidade substitutiva ou secundária e outro de homossexualidade verdadeira ou neurose sexual" (Adrados, 1964, p.65). A partir de Melaine Klein e Sigmund Freud, Franco Filho (1972) afirmou:

Na realidade, a homossexualidade não pode ser encarada desse prisma, em que pese seja colocada como comportamento anormal. Ela não é uma doença, mas um conjunto de sintomas. Ou em outras palavras, é uma defesa, uma maneira do ego se proteger face a determinadas ansiedades (p.5, grifos no original). 
Ainda na esteira da Psicanálise, alguns métodos e técnicas surgiam, como, por exemplo, o uso do Psicodiagnóstico de Rorschach (Adrados, 1964; Van Kolch, 1972a; Van Kolch, 1972b). Pela apropriação de tais recursos teóricos e instrumentais, a homossexualidade se produzia como um objeto cuja explicação poderia se encontrar no ambiente social, já que "a experiência clínica [levava] a uma quase impossibilidade de caracterizar e definir 'homossexualismo' como um grupo nosológico à parte" (Van Kolch, 1972b, p.123). Assim, a homossexualidade foi explicada, à época, com base em "influências negativas do ambiente" (Baez-Sampaio, 1962 , p.5) e em um ambiente familiar “... em que as relações entre os pais estavam tendo seus efeitos negativos no desenvolvimento sexual do adolescente" (p.11). Nessa direção, o modelo de explicação da homossexualidade baseou-se em questões psicossociais.

A concepção de um sujeito indissociável do ambiente orientava tanto os critérios diagnósticos quanto os métodos e as técnicas psicológicas utilizadas nos casos de homossexualidade. Boa parte do diagnóstico de homossexualidade foi baseado no uso de métodos e técnicas psicológicas como entrevistas, testes psicológicos de personalidade e, ainda, escala de inteligência. Os testes de personalidade mais utilizados, nas fontes (Adrados, 1964; Baez-Sampaio, 1962; Silva, 1967), foram o Psicodiagnóstico Miocinético (P.M.K.), Rorschach e Teste de Apercepção Temática (T.A.T). Inclusive, havia revisões de literatura sinalizando os resultados de diferentes medidas para o diagnóstico específico da homossexualidade (Van Kolch, 1972a; Van Kolch, 1972b). Quanto à inteligência, parece ter sido dada certa ênfase em tal aspecto, ao ser compreendida para além das avaliações contidas nos testes de personalidades, recorrendo ao uso da Escala de Inteligência Wechsler para Crianças (W.I.S.C). O tratamento indicado, para todos os casos, foi a psicoterapia, tanto para o sujeito com "tendências homossexuais" ou "portador de homossexualidade" como para sua família, e.g., "portadores de homossexualidade substitutiva ou secundária, quando submetidos a um tratamento psicoterápico competente e conveniente orientados podem regredir e enquadrar sua conduta dento da normalidade" (Adrados, 1964, p.68). Além disso, um longo acompanhamento psicoterápico, por volta de dois anos, mostrou que "os resultados eram visíveis", ou seja, "sua melhora foi visível. Na ultima vez que o vimos, falou-nos sobre a mudança de sua atitude; fez comparações com seu comportamento anterior" (Silva, 1967, p.93). Portanto, os métodos e técnicas psicológicas foram utilizados para o diagnóstico de homossexualidade, bem como sua "solução".

Assim, no passado, podemos observar dois tipos de explicação para a homossexualidade. Por um lado, explicações marcadamente biologicistas que permitiriam uma história natural de sua etiopateogenia (e.g., Epps, 1972; Simon, 1972). Por outro, um 
modelo de explicação psicossocial da homossexualidade em que ela foi compreendida como uma má conduta social, podendo ser ajustada (e.g., Adrados, 1964, Silva, 1967). Todavia, o mesmo não poderia ser feito na contemporaneidade, conforme propõe o Projeto de Decreto Legislativo No. 234. Isso implicaria em uma leitura apressada dos debates passados na área da Psicologia e, em nosso entendimento, presentista, que poderia corroborar práticas antiéticas e pouco científicas.

\section{Considerações finais}

Este trabalho apresentou dois debates contemporâneos no campo da Psicologia, a saber: a delimitação de sua subordinação à Medicina no atendimento em saúde e a terapêutica de orientações homossexuais. Eles foram abordados a partir de uma mirada ao seu passado, no Brasil como forma de endereçar uma resposta à pergunta: "História da Psicologia, por quê?" A resposta que estimamos ter produzido, a partir de uma perspectiva não presentista, foi: o exame da história da Psicologia nos habilita compreender o passado e em como ele impacta a contemporaneidade. Portanto, a pesquisa em História da Psicologia, se torna condição sine qua non para problemáticas atuais da Psicologia. Dessa forma, os dois debates apresentados nos permitiram exemplificar como produzir e pensar a história na Psicologia e a Psicologia na história, no Brasil, auxiliando-nos no entendimento das possíveis atualizações que tais fenômenos fazem, no presente.

Foi possível analisar, ainda, dois aspectos da História da Psicologia. Primeiramente, condições históricas que permitiram a regulamentação da profissão do psicólogo, no país, bem como a apropriação de objetos, métodos e técnicas psicológicas do profissional psicólogo. Isso se deu pela da Lei n. 4.119 e de vários outros dispositivos e resoluções que foram criados ao longo da história da profissão do psicólogo. Identificamos, portanto, que a delimitação de objeto guardava relação com os problemas de ajustamento que os psicólogos deveriam solucionar. Os métodos e técnicas psicológicas, também relacionados à solução dos problemas de ajustamentos, permanecem sem definições. Em segundo lugar, a construção de discursos e práticas psicológicas voltados às pessoas homossexuais, sobretudo no que diz respeito às explicações psicossociais de seu sofrimento. Os resultados mostraram que, ao longo da história, a Psicologia, em um primeiro momento, tratou a homossexualidade como uma doença mental que deveria ser solucionada por meio de psicoterapia, como forma de reversão dos sintomas. Contemporaneamente, a Psicologia entende ter 0 
compromisso ético com as pessoas homossexuais, a fim de não promover estigmas, como "cura gay".

Por fim, acreditamos ser válido indicar limitações metodológicas de nossa proposta. Poderíamos ter endereçado nossa resposta à pergunta "História da Psicologia, por quê?" a partir de uma mirada meta-historiográfico e, portanto, ter recorrido a debates contemporâneos do campo que delimitamos que é fazer História da Psicologia. Ao não adotarmos tal perspectiva, nos limitamos a problematizar apenas dois exemplos que nos auxiliariam a compreender a pertinência do ensino e da pesquisa em História da Psicologia. Dessa forma, nosso estudo encontrou algumas limitações, as quais se relacionam, e. g., a quantidade de exemplos, bem como, em sua abrangência (objetos psicológicos vinculados ao campo Clínico e da Saúde), além do manejo de fontes primárias, restrito a legislações e artigos de apenas dois periódicos em um período delimitado de tempo. Estudos futuros poderão expandir nossas fontes, além de identificar e analisar vários outros fenômenos ocorridos, na História da Psicologia, que desvelem as várias histórias que ela contém em si mesma. Todavia, estimamos que, ao final, tenhamos apresentado a História da Psicologia como uma ferramenta que nos auxilia na compreensão de certas escolhas do passado e, de maneira não presentista ou anacronista, propicia que vejamos rupturas e permanências, na história, contribuindo com reflexões sobre questões contemporâneas.

\section{Referências}

Adrados, I. (1964). Estudo da homossexualidade mediante o teste de Rorschach. Arquivos Brasileiros de Psicotécnica, 16(1), 55-74.

Arruda, E. (1968). Estado atual da promoção e defesa da saúde mental. Arquivos Brasileiros de Psicotécnica, 20(2), 35-45.

Baez-Sampaio, H. A. (1962). A Influência do Ambiente familiar no desenvolvimento psicossexual do adolescente. Arquivos Brasileiros de Psicotécnica, 14(2), 5-12.

Baptista, M. T. D. S. (2009). I deias divulgadas em São Paulo durante o processo histórico da regulamentação da profissão de psicólogo. Temas em Psicologia, 17(1). Recuperado de http: //pepsic.bvsalud.org/scielo.php?script=sci_abstract\&pid=S 1413-389X2009000100011

Baptista, M. T. D. S. (2010). A regulamentação da profissão psicologia: documentos que explicitam o processo histórico. Psicologia: Ciência e Profissão, 30(n. especial), 170-191. Recuperado de http://www.scielo.br/pdf/pcp/v30nspe/v30speca08.pdf 
Barnes, M. E., \& Greer, S. (2014). Does the future have a history of psychology? A report on teaching, research, and faculty positions in Canadian universities. History of Psychology, 17(2), 159-169. doi: $10.1037 / a 0035335$

Brasil. (1962). Lei n. 4.119, de 27 de agosto de 1962. Dispõe sobre os cursos de formação em Psicologia e regulamenta a profissão de Psicólogo. Diário Oficial da União. Brasília, DF: Presidência da República. Recuperado de http://www. planalto.gov.br/ccivil_03/leis/1950-1969/l4119.htm

Brasil. (1999). Resolução CFP № 001/99. Estabelece normas de atuação para os psicólogos em relação à questão da orientação sexual. Brasília, DF: Conselho Federal de Psicologia. Recuperado de https://site.cfp.org.br/wpcontent/uploads/1999/03/resolucao1999_1.pdf

Brasil. (2000). Resolução CFP no 10/00. Especifica e qualifica a Psicoterapia com pratica do psicólogo. Brasília, DF: Conselho Federal de Psicologia. Recuperado de https://site.cfp.org.br/wpcontent/uploads/2000/12/resolucao2000_10.pdf

Brasil. (2000). Resolução CFP no 18/00. Constitui a consolidação das resoluções do Conselho Federal de Psicologia. Brasília, DF: Conselho Federal de Psicologia. Recuperado de https: //atosoficiais.com. br/cfp/resolucao-cfp-n-18-2000institui-a-consolidacao-das-resolucoes-do-conselho-federal-depsicologia

Brasil. (2002). Projeto de Lei do Senado no 268. Dispõe sobre o exercício da Medicina. Brasília, DF: Senado Federal. Recuperado de https://www25.senado.leg. br/web/atividade/materias//materia/53750

Brasil. (2006). Projeto de Lei no 7703/2006. Define a área de atuação, as atividades privativas e os cargos privativos de Médico resguardadas as competências próprias das diversas profissões ligadas à área de saúde. Projeto chamado de "Ato Médico". Brasília, DF: Câmara dos Deputados. Recuperado de http://www.camara.gov.br/proposicoesWeb/fichadetramitacao?i dProposicao $=339409$

Brasil. (2007). Resolução CFP no 013/2007. Institui a Consolidação das Resoluções relativas ao Título Profissional de Especialidades em Psicologia e dispõe sobre normas e procedimentos para seu registro. Brasília, DF: Conselho Federal de Psicologia. Recuperado de https://site.cfp.org.br/wpcontent/uploads/2008/08/Resolucao_CFP_nx_013-2007.pdf

Brasil. (2011). Projeto de Decreto Legislativo $n$ o $234 / 2011$. Susta a aplicação do parágrafo único do art. 3o e 0 art. 4o, da Resolução do Conselho Federal de Psicologia n. 1/99 de 23 de Março de 1999, que estabelece normas de atuação para os psicólogos em relação à questão da orientação sexual... 
Brasília, DF: Câmara dos Deputados. Recuperado de http://www.camara.gov.br/proposicoesWeb/fichadetramitacao?i dProposicao $=505415$

Brasil. (2013). Lei n. 12.842, de 10 de Julho de 2013. Dispõe sobre o exercício da Medicina. Diário Oficial da União. Brasília, DF: Presidência da República. Recuperado de http://www.planalto.gov.br/ccivil_03/_Ato20112014/2013/Lei/L12842.htm

Brasil. (2017). Projeto de Lei no 7726/2017. Torna a psicoterapia atividade privativa de psicólogos ou de médicos no exercício da psiquiatria. Brasília, DF: Câmara dos Deputados. Recuperado de http://www.camara.gov. br/proposicoesWeb/fichadetramitacao?i dProposicao $=2139105$

Brasil. Ministério da Educação e da Cultura [MEC]. (2011). Diretrizes Curriculares Nacionais. Recuperado de http://portal.mec.gov.br/observatorio-da-educacao/323secretarias-112877938/orgaos-vinculados-82187207/12991diretrizes-curriculares-cursos-de-graduacao

Brozek, J., \& Massimi, M. (1998). Historiografia da Psicologia Moderna: a versão brasileira. São Paulo: Edições Loyola.

Buchanan, R. D. (2003). Legislative warriors: American psychiatrists, psychologists, and competing claims over psychotherapy in the 1950s. J ournal of the History of the Behavioral Sciences, 39(3), 225-249. doi: 10.1002/jhbs. 10113

Castro, A. C., \& Alcântara, E. S. (2011). Associação Brasileira de Psicologia Aplicada (ABRAPA) - 1993. In A. M. Jacó (Org.), Dicionário Histórico de Instituições de Psicologia no Brasil (pp. 45-47). Rio de Janeiro: I mago.

Conselho Federal de Psicologia [CFP]. (2017, Setembro 16). CFP vai recorrer da sentença sobre Resolução 01/99. Conselho Federal de Psicologia: Notícias. Recuperado de https://site.cfp.org.br/resolucao-cfp-0199-e-mantida-emdecisao-judicial/

Danziger, K. (1985). Towards a conceptual framework for a critical history of psychology. In H. Carpintero \& J. M. Peiro (Orgs.), Psychology in its historical context: Essays in honour of $J$. Brozek (pp. 99-107). Valencia: Monografias de la Revista de Historia de la Psicologia.

Danziger, K. (1993). Psychological objects, practice, and history. Annals of Theoretical Psychology, 8, 15-47.

Danziger, K. (2003). Where theory, history and philosophy meet: The biography of psychological objects. In D. B. Hill \& M. J. Kral (Orgs.), About psychology: Essays at the crossroads of history, theory and philosophy (pp. 19-33). Albany: SUNY Press.

Daston, L. (Org.) (2000). Biographies of scientific objects. Chicago: University of Chicago Press. 
Dickinson, T. (2015). 'Curing Queers' - Mental nurses and their patients, 1935-74. Manchester: Manchester University Press.

Dorin, L. (1980). Enciclopédia de Psicologia Contemporânea: Dicionário Ilustrado de Psicologia. São Paulo: Livraria Editora I racema LTDA.

Epps, D. (1972). Aspectos genéticos e endócrinos da interesexualidade e da homossexualidade. Boletim de Psicologia, 24, 11-17.

Erzen, T. (2006). Straight to Jesus: Sexual and Christian conversions in the ex-gay movement. California: California University Press.

Escardó, F., \& Giberti, E. (1961). A saúde mental na primeira infância. Arquivos Brasileiros de Psicotécnica, 13(1), 5-15.

Fausto, B. (2002). História do Brasil. Brasília: Huzak.

Fierro, C. (2016). Enseñanza de la Historia de la Psicología y Formación de Psicólogos: Desarollos y debates actuales en Argentina y el mundo. Peru: Sociedad Peruana de Historia de la Psicología, Adrus Editores.

Franco Filho, O. M. (1972). Caracterização e gênese da homossexualidade. Boletim de Psicologia, 24, 3-9.

Goodwin, C. J. (2012). A history of modern psychology (4a ed). Nova Jersey: John Wiley \& sons, Inc.

Jacó-Vilela, A. M. (1999). Formação do psicólogo: um pouco de história. Interações: Estudos e Pesquisas em Psicologia, 4(8), 79-91.

Jansz, J., \& van Drunen, P. (2004). A social history of Psychology. Oxford: Blackwell Publishing.

Klappenbach, H. (2000a). El titulo profesional de psicologo en Argentina: Antecedentes historicos y situación actual. Revista Latinoamericana de Psicología, 32(3), 419-446.

Klappenbach, H. (2000b). El psicoanálisis en los debates sobre el rol del psicólogo: Argentina, 1960-1975. Revista Universitaria de Psicoanálisis, 2, 191-227.

Luchese, T. A. (2014). Modos de fazer História da Educação: Pensando a operação historiográfica em temas regionais. História da Educação, 18(43), 145-161. doi:10.1590/S223634592014000200009

Mariano, L. R. P. G. (2016). Classificando o sofrimento e medicalizando fenômenos: Psicanálise e Psiquiatria frente ao DSM (Dissertação de Mestrado). Universidade Católica Dom Bosco, Campo Grande, Mato Grosso do Sul, Brasil.

Massimi, M. (2010). O processo de institucionalização do saber psicológico no Brasil no século XIX. In A. M. Jacó-Vilela, A. A. I. Ferreira, \& F. T. Portugal (Orgs.), História da Psicologia: Rumos e percursos (pp. 159-168). Rio de Janeiro: Nau Ed.

Mota, A. M. D. G. F., Castro Neto, E., \& Miranda, R. L. (2016). "Problemas de Ajustamento" e "Saúde Mental": Controvérsias 
em torno de um objeto psicológico. In L. P. Almeida (Org.), Políticas públicas, cultura \& produções sociais. Campo Grande: Editora UCDB.

Mota, A. M. D. G. F., \& Miranda, R. L. (2017). Desvelando Estilos de Pensamento: 'Diagnósticos' nos Arquivos Brasileiros de Psicotécnica (1949-1968). In L. Almeida, A. O. S. A. Duarte, M. F. P. Cassimiro, \& R. H. F. Campos (Orgs), Psicologia, educação e o debate ambiental: questões históricas e contemporâneas. Belo Horizonte FAE/UFMG; CDPHA.

Penna, A. G. (n.d.). Linguagem, personalidade e terapia. Rio de Janeiro: Eldorado.

Pickren, W., \& Rutherford, A. (2010). A history of modern psychology in context. Nova Jersey: J ohn Wiley \& sons.

Portugal, F. T., Facchinetti, C., \& Castro, A. C. (2018). História social da Psicologia. Rio de Janeiro: Nau Editora.

Russo, J. A. (2010). O movimento psicanalítico brasileiro. In A. M. Jacó-Vilela, A. A. I. Ferreira, F. T. Portugal (Orgs.), História da Psicologia: Rumos e percursos (pp. 413-424). Rio de Janeiro: Nau.

Schultz, D. P., \& Schultz, S. E. (2015). História da psicologia moderna (10a ed.). São Paulo: Cengage Learning.

Silva, A. R. (1967). Um caso de homossexualismo psíquico. Arquivos Brasileiros de Psicotécnica, 19(1), 89-94.

Simon, R. (1972). Prevenção da homossexualidade masculina. Boletim de Psicologia, 24, 19-50.

Van Kolck, O. L. (1972a). O homossexualismo através dos testes psicológicos em geral. Boletim de Psicologia, 24, 69-104.

Van Kolck, T. (1972b). Homossexualidade masculina no psicodiagnóstico de Rorschach. Boletim de Psicologia, 24, 123145.

Vaughn-Blount, K., Rutherfor, A., Baker, D., \& Johnson, D. (2009). History's mysteries, demystified: Becoming a psychologisthistorian. The American Journal of Psychology, 122(1), 117129.

\footnotetext{
Endereço para correspondência

Ana Maria Del Grossi Ferreira Mota

Universidade Católica Dom Bosco - UCDB

Av. Tamandaré, 6000, Jardim Seminário, CEP 79117-900, Campo Grande - MS, Brasil

Endereço eletrônico: amdelgrossi@gmail.com

\section{Bianca dos Santos Cara}

Universidade Católica Dom Bosco - UCDB

Av. Tamandaré, 6000, Jardim Seminário, CEP 79117-900, Campo Grande - MS, Brasil

Endereço eletrônico: biancacara@gmail.com
} 
Ana Maria Del Grossi Ferreira Mota, Bianca dos Santos Cara, Rodrigo Lopes Miranda

\section{Rodrigo Lopes Miranda}

Universidade Católica Dom Bosco - UCDB

Av. Tamandaré, 6000, Jardim Seminário, CEP 79117-900, Campo Grande - MS, Brasil

Endereço eletrônico: rlmiranda@ucdb.br

Recebido em: 18/12/2018

Reformulado em: 18/02/2019

Aceito em: 22/02/2019

\section{Notas}

* Psicóloga, especialista em Saúde Mental, Mestre em Psicologia e Doutoranda em Psicologia pela Universidade Católica Dom Bosco (UCDB). Bolsista do Doutorado CAPES/PROSUC.

** Psicóloga, Especialista em Psicopedagogia, Mestre em Psicologia da Saúde pela Universidade Católica Dom Bosco (UCDB).

*** Psicólogo, Doutor em Educação (UFMG), Professor do Programa de PósGraduação em Psicologia da Universidade Católica Dom Bosco (UCDB). 